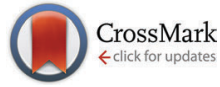

Cite this: Phys. Chem. Chem. Phys., $2014,16,26570$

\title{
Ligand/cluster/support catalytic complexes in heterogeneous ultrananocatalysis: NO oxidation on $\mathrm{Ag}_{3} / \mathrm{MgO}(100)$
}

\author{
Luca Sementa, ${ }^{a}$ Giovanni Barcaro, ${ }^{a}$ Fabio R. Negreiros ${ }^{a}$ and Alessandro Fortunelli*ab \\ In the present work we explore via first-principles simulations whether the ligand/cluster/support \\ catalytic complex generated by $\mathrm{CO}$ oxidation over silver trimers deposited on the regular $\mathrm{MgO}(100)$ \\ surface - i.e. a $\mathrm{Ag}_{3} /$ carbonate or $\mathrm{Ag}_{3}\left(\mathrm{CO}_{3}\right) / \mathrm{MgO}(100)$ species - can be used as a catalyst in a different \\ reaction: the selective oxidation of $\mathrm{NO}$ to $\mathrm{NO}_{2}$ (or $\mathrm{NOox}$ ). The $\mathrm{Ag}_{3}\left(\mathrm{CO}_{3}\right) / \mathrm{MgO}(100)$ complex is first \\ shown to be reasonably stable at room temperature in terms of both disaggregation and sintering, and \\ that it can be generated from $\mathrm{Ag}_{3}$ adsorbed onto an oxygen vacancy defect of the regular $\mathrm{MgO}(100)$ \\ surface under oxidation conditions. It is then found that the $\mathrm{Ag}_{3}\left(\mathrm{CO}_{3}\right) / \mathrm{MgO}(100)$ species transforms \\ under NOox conditions into an even more complex aggregate, a mixed carbonate/double-nitrite \\ $\mathrm{Ag}_{3}\left(\mathrm{CO}_{3}\right)\left(\mathrm{NO}_{2}\right)_{2} / \mathrm{MgO}(100)$ species, which can then act as an efficient catalyst of NOox. It is noteworthy \\ that under NOox reaction conditions a different ligand/cluster/support catalytic complex is formed with \\ respect to the original COox one. These findings prove the diversity of the catalytic chemistry of sub- \\ nanometer (or ultranano) metal clusters deposited on oxide substrates, associated with the formation of \\ many different ligand/cluster/support aggregates, the vast amount of combinatorial possibilities thus \\ opening, and the need for computational approaches to perform systematic structural and stoichio- \\ metric searches in order to cope with such a multiform diversity.
}

Received 16th May 2014,
Accepted 7th August 2014
DOl. $10.1039 / c 4 c p 02135 e$

www.rsc.org/pccp explored extensively so that a trial-and-error optimization approach has been exhausted (whereas ultrananoclusters may show novel energetics and thus a different reaction landscape), and there is an atom-economic use of chemical elements, especially precious metals. ${ }^{6}$

Although much experience has been accumulated over the last 10 years at both the theoretical and experimental levels and some general concepts have started emerging, ${ }^{7,8}$ a comprehensive framework is still lacking, especially in terms of reaction mechanisms, which - due to the small size of the metal clusters, their intermediate character between molecular and metallic aggregates, and the proximity effect of the oxide support - can be different and sometimes peculiarly novel with respect to extended crystal surfaces or even facets of slightly larger nanoparticles. In this respect, one important point which is still under debate regards coverage effects, i.e., whether reaction mechanisms change from low to high coverage, i.e., whether a different chemistry takes place when multiple ligand adsorption occurs (and is explicitly included in the theoretical modeling). ${ }^{9}$ This point has been investigated by us in previous work ${ }^{7,10}$ in which we studied e.g. the oxidation of $\mathrm{CO}$ to $\mathrm{CO}_{2}$ (or COox in brief) catalyzed by $(\mathrm{Ag}-\mathrm{Au})_{3}$ trimers deposited on the regular $\mathrm{MgO}(100)$ oxide surface. ${ }^{10}$ We found that in the case of $\mathrm{Ag}_{3} /$ $\mathrm{MgO}(100)$ (this is also true for $\mathrm{Ag}_{2} \mathrm{Au}$ ), COox does not proceed 
on the bare metal cluster, but rather a ligand/cluster/support $\mathrm{Ag}_{3}\left(\mathrm{CO}_{3}\right) / \mathrm{MgO}(100)$ complex is formed in situ and under very general reaction conditions, and this latter species is the real catalytically active complex which processes $\mathrm{CO}$ into $\mathrm{CO}_{2}$. We describe this species as a ligand/cluster/support complex because it is a complex aggregate made of the metal ultrananocluster plus adsorbed ligands - in the present case, a carbonate ligand formed via the reaction of $\mathrm{CO}$ with $\mathrm{O}_{2}$ and the successive removal of an oxygen adatom by another CO molecule in which both the metal cluster and the ligands are interacting with the oxide support so strongly that it is difficult to separate the individual interaction components.

In the present article we show that the $\mathrm{Ag}_{3}\left(\mathrm{CO}_{3}\right) / \mathrm{MgO}(100)$ species is naturally formed from $\mathrm{a} \mathrm{Ag}_{3}$ trimer adsorbed onto an $\mathrm{MgO}(100)$ surface exhibiting an oxygen vacancy defect after exposure to $\mathrm{O}_{2}$, which thus represents an alternative synthesis path and supports the realistic existence of such a species, and furthermore that it is also reasonably robust with respect to disaggregation and sintering - a crucial issue when dealing with ultrananocatalysts.

Then we take one step further, and investigate whether this catalytic complex originally associated with COox over $\mathrm{Ag}_{3} / \mathrm{MgO}(100)$ can be used in a different reaction. In other words, we assume to have "pre-treated" our $\mathrm{Ag}_{3} / \mathrm{MgO}(100)$ system with $\mathrm{CO}$ and $\mathrm{O}_{2}$ prior to running the catalytic reaction of interest, thus forming the $\mathrm{Ag}_{3}\left(\mathrm{CO}_{3}\right) / \mathrm{MgO}(100)$ ligand/cluster/support complex, which is then used as a heterogeneous catalyst in situ but under different reaction conditions. What we are trying to emulate here is an in situ catalyst pretreatment which is the natural counterpart of what is usually done in the preparative step of real-world heterogeneous catalysis, something which is often non-rationalized and described as 'black magic'. ${ }^{11}$

In terms of catalytic reaction, we focus on the selective oxidation of $\mathrm{NO}$ to $\mathrm{NO}_{2}\left(\mathrm{NO}+1 / 2 \mathrm{O}_{2} \rightarrow \mathrm{NO}_{2}\right.$, or NOox in brief). It should be noted that extended systems, like the $\mathrm{Ag}(111)$ surface, are not expected to promote this reaction, ${ }^{12}$ so that the results to be shown in the following will prove once more the peculiarity of ultrananocluster chemistry. The NOox reaction must occur together with COox and the oxidation of hydrocarbons to $\mathrm{H}_{2} \mathrm{O}$ and $\mathrm{CO}_{2}$ and of sulfur-containing species to $\mathrm{SO}_{2}$ e.g. in the treatment of Diesel exhaust gases (thus, under oxygen-rich conditions) and is highly desirable, as it enhances the efficiency of the successive steps of the treatment, among which are soot oxidation, ${ }^{13}$ the selective catalytic reduction of $\mathrm{NO}_{2}$ to $\mathrm{N}_{2}$ with $\mathrm{NH}_{3}$ (or urea), ${ }^{14,15}$ etc. A strong oxidation catalyst, the Diesel Oxidation Catalyst (DOC), ${ }^{15}$ is placed upstream of the other catalysts to promote the COox, NOox, hydrocarbon and sulfur oxidation reactions. Pt-based catalysts are employed in commercial converters, ${ }^{15}$ but, among several issues, one is the replacement of $\mathrm{Pt}$ with less expensive elements. In this perspective, $\mathrm{Ag}_{3}$ is a good candidate because of the lower price and larger abundance of $\mathrm{Ag}$ with respect to $\mathrm{Pt}$, and the atom-economy of the catalyst in a subnanometer form. Similarly to COox ones, NOox catalysts suffer from insufficient activity at low temperature, which is detrimental e.g. in the start-up phase of any automotive engine and in Diesel engines, in particular (in which, ideally, the catalyst should work at temperatures as low as $175{ }^{\circ} \mathrm{C}$ ). For definitiveness, we thus assume to work under the following conditions: room temperature, $\mathrm{O}_{2}$ pressure $=0.2 \mathrm{~atm}$, $\mathrm{NO}$ and $\mathrm{NO}_{2}$ pressure $=0.002$ atm. For a complete investigation, the presence of other species not included here such as water and sulfur oxides should be considered - in the present preliminary work we limit ourselves to an exploratory study whose results seem to be promising, and defer a full investigation to future work. As in previous studies, ${ }^{10,16}$ the support selected here is $\mathrm{MgO}(100)$, which is an idealized oxide system but can be taken as a reasonable model of a surface of simple oxide.,16

What we find is something surprising but of possible general significance. While the first NOox step proceeds via a route very similar to the homologous step of COox over $\mathrm{Ag}_{3}\left(\mathrm{CO}_{3}\right)$ / $\mathrm{MgO}(100)$, after an oxygen adatom is formed on $\mathrm{Ag}_{3}\left(\mathrm{CO}_{3}\right) /$ $\mathrm{MgO}(100)$ in the presence of $\mathrm{NO}$ and $\mathrm{O}_{2}$ the reaction takes a completely different path, finally leading to a mixed carbonate/ double-nitrite $\mathrm{Ag}_{3}\left(\mathrm{CO}_{3}\right)\left(\mathrm{NO}_{2}\right)_{2} / \mathrm{MgO}(100)$ complex which then acts as the real catalyst of NOox. In other words, also in the case of NOox catalyzed by $\mathrm{Ag}_{3}\left(\mathrm{CO}_{3}\right) / \mathrm{MgO}(100)$ we do find a highligand-coverage complex as the real catalytic species, albeit different from that purposely pre-formed from a COox run on the $\mathrm{Ag}_{3} / \mathrm{MgO}(100)$ system. We then arrive at three main points. First, we confirm that the formation of the ligand/cluster/ support complex is generally operative in heterogeneous ultrananocatalysis. ${ }^{7}$ Second, from the present work the great structural and stoichiometric freedom of heterogeneous ultrananocatalysts emerges, implying from the theoretical point of view the need for systematic structural searches that are able to single out which ligand/cluster/support catalytic species is eventually created under the given experimental conditions. ${ }^{16}$ Achieving this knowledge will greatly enhance the predictive capability and thus the impact of computational approaches on ultrananocatalysis, and possibly also on nanocatalysis, in general. Third, a vast combinatorial set of possible pairs of catalytic-complex/catalytic-reaction opens, of which the present results offer only a rapid glimpse.

The article is organized as follows. Section 2 describes the computational details, Section 3 presents the results and discussion, and Section 4 summarizes our conclusions.

\section{Computational details}

All density-functional theory (DFT) calculations are performed using the plane-wave Quantum Espresso package. ${ }^{17}$ The PerdewBurke-Ernzerhof $(\mathrm{PBE})^{18}$ exchange-correlation functional is used together with ultrasoft pseudopotentials ${ }^{19}$ and energy cutoffs of 40 Ry and 320 Ry for the wave function and electronic density, respectively. Structural optimizations and transition state searches are carried out in a spin-unrestricted formalism, using $3 \times 4$ cells with $2 \mathrm{MgO}$ layers (kept frozen during structural optimizations), an empty space of $17 \AA$ between replicated cells and a Brillouin zone sampled at the Gamma point only. In order to describe transition state energetics, reaction barriers are evaluated using a nudged elastic band $(\mathrm{NEB})^{20}$ transition state algorithm using the Broyden scheme and 5 intermediate images. It should be noted that some 
spin contamination is found in our DFT calculations, whose effect on reaction energy differences and energy barriers is, however, difficult to quantify.

$\mathrm{Ab}$ initio molecular dynamics (MD) is performed using the CP2K $\operatorname{code}^{21}$ whose DFT algorithms are based on a hybrid Gaussian/Plane-Wave scheme (GPW) developed by Lipper, Hutter and Parrinello. ${ }^{22}$ We choose pseudopotentials derived by Goedecker, Teter and Hutter (GTH) to describe the core electrons ${ }^{23}$ and DZVP basis sets ${ }^{24}$ to represent the DFT Kohn-Sham orbitals. The cut-off for the auxiliary plane wave representation of the density is 300 Ry. Each dynamics is followed for 10-20 ps with a time step of 0.5 fs during which the temperature is controlled by Nosé-Hoover chain thermostats. ${ }^{25}$ As in the Quantum Espresso calculations, the PBE functional is used. ${ }^{18}$ To avoid the interaction between periodic images we use $4 \times 4$ cells with $2 \mathrm{MgO}$ layers kept frozen during the dynamics and an empty space of $17 \AA$ between replicated cells.

In terms of sampling the reactive potential energy surface of the investigated systems, CPU-time limitations did not allow us to conduct a complete structural $\operatorname{search}^{16}$ as performed in previous work. ${ }^{10}$ We therefore use a biased search based on a few simplifying assumptions and constraints, the two major ones being that we do not consider the consecutive adsorption of two NO molecules in the stoichiometry moves not separated by adsorption of an $\mathrm{O}_{2}$ molecule (which is reasonable at a $\mathrm{NO}: \mathrm{O}_{2}$ ratio of $1: 100$ as assumed here) and we do not check systematically the structural neighborhood of all intermediate species in the proposed catalytic cycle. While it is possible that alternative reaction paths are so missed, due to the complex and fluxional chemistry occurring over the $\mathrm{Ag}_{3}\left(\mathrm{CO}_{3}\right) / \mathrm{MgO}(100)$ system under NOox conditions, the proposed catalytic cycle represents a possibility which can be operative under appropriate conditions.

\section{Results and discussion}

\section{A. Database of structural motifs for ligand adsorption onto} $\mathrm{Ag}_{3} / \mathrm{MgO}(100)$

Before going into the details of our results, it is useful to define a nomenclature of adsorption modes of ligand molecules onto the $\mathrm{Ag}_{3} / \mathrm{MgO}(100)$ cluster. In addition to simplifying the following discussion, this is intended to contribute to creating a database $^{26}$ of structural motifs, which is of great help in systematic structural searches such as global optimization ones, see e.g. 'system comparison' and 'structural recognition' techniques. $^{27}$ Fig. 1 presents such a database of commonly occurring adsorption modes. $\mathrm{NO}$ and $\mathrm{O}_{2}$ can adsorb onto the tip ('top', Fig. 1a and c, respectively) or at the base ('base', Fig. $1 \mathrm{~b}$ and $\mathrm{d}$, respectively) of the $\mathrm{Ag}_{3}$ triangle, where the base is defined to be closer to the oxide than the tip. For $\mathrm{NO}_{2}$ the situation is more complicated, because - if the 'top' mode (with $\mathrm{NO}_{2}$ interacting with the metal cluster via a single $\mathrm{N}-\mathrm{Ag}$ bond) is still available due to the large distance from the oxide surface (Fig. 1i) -, the 'base' mode is usually meta-stable and transforms either into a two-fold or bidentate adsorption mode (with both $\mathrm{N}$ and one of the

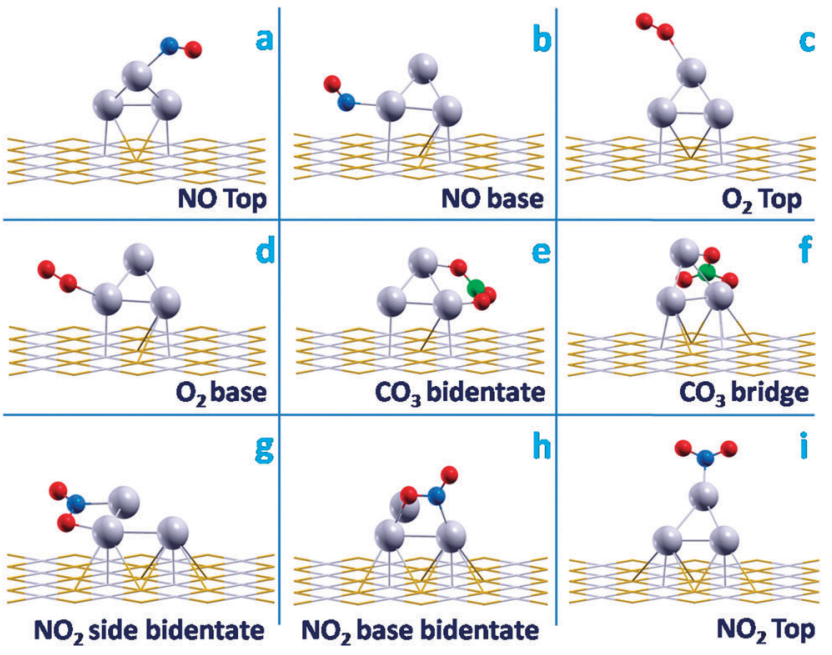

Fig. 1 Pictorial description and nomenclature of adsorption modes of $\mathrm{NO}, \mathrm{O}_{2}, \mathrm{CO}_{3}$, and $\mathrm{NO}_{2}$ molecules onto $\mathrm{Ag}_{3} / \mathrm{MgO}(100)$. Silver atoms are shown as grey spheres, nitrogen atoms as blue spheres, and oxygen in the ligands as red spheres. The atoms of the $\mathrm{MgO}(100)$ support (only the first layer is explicitly shown) are depicted in the 'stick' mode with oxygens in gray and magnesium atoms in orange.

two $\mathrm{O}$ atoms interacting with two different $\mathrm{Ag}$ atoms) which can in turn be distinguished into a base adsorption ('base bidentate', Fig. 1h) or a side adsorption ('side bidentate', Fig. 1g), or a direct interaction with the substrate (a 'bridge' mode) which is better exemplified for the $\mathrm{CO}_{3}$ carbonate ligand. $\mathrm{CO}_{3}$ can in fact adsorb in a two-fold or bidentate adsorption ('bidentate', Fig. 1e) mode as in the original $\mathrm{Ag}_{3}\left(\mathrm{CO}_{3}\right) / \mathrm{MgO}(100)$ complex, whose adsorption mode is different from that of $\mathrm{NO}_{2}$ in that two $\mathrm{O}$ atoms of the carbonate interact with two different $\mathrm{Ag}$ atoms, but this usually most stable configuration is in close competition with an adsorption mode ('bridge', Fig. 1f) in which only one $\mathrm{O}$ atom is adsorbed at a bridge site of the $\mathrm{Ag}_{3}$ triangle, whereas the other two $\mathrm{O}$ atoms are linked to $\mathrm{Mg}^{++}$cations of the oxide substrate. Such a great structural freedom can also be rationalized in terms of electrostatic interactions between the ligand/cluster ad-species and the chargeseparated substrate. ${ }^{9,16}$ This form of ionic interaction occurs not only when it is obviously apparent, as when $\mathrm{O}$ atoms in the catalytic aggregate lie on top of $\mathrm{Mg}^{++}$sites of $\mathrm{MgO}(100)$, but also more subtly because the electric field generated by the ionic substrate interacts with dipole moments developing in the ligand/cluster complex. ${ }^{10}$ In this sense it is appropriate to speak of ligand/cluster/support complexes.

\section{B. Stability of the $\mathrm{Ag}_{3}\left(\mathrm{CO}_{3}\right) / \mathrm{MgO}(100)$ ligand/cluster/support catalytic complex}

We start our investigation from the $\mathrm{Ag}_{3}\left(\mathrm{CO}_{3}\right) / \mathrm{MgO}(100)$ ligand/ cluster/support catalytic species which has been shown to be produced in situ and under very general reaction conditions in the oxidation processes of $\mathrm{CO}$ into $\mathrm{CO}_{2}$ over the $\mathrm{Ag}_{3} / \mathrm{MgO}(100)$ system, ${ }^{10}$ see Fig. 2a. One very general question which is particularly relevant when dealing with metal ultrananoclusters concerns the stability of such a species, i.e., whether the given catalyst is stable with respect to disaggregation and sintering. ${ }^{7,9}$ 

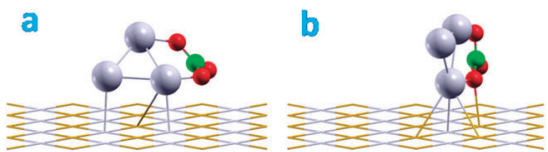

c

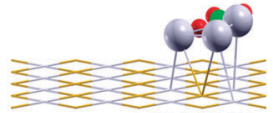

$M D 300^{\circ} \mathrm{K}$
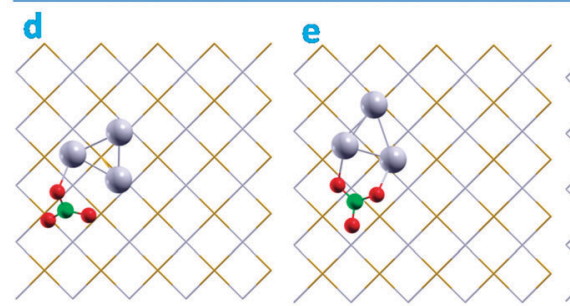

f

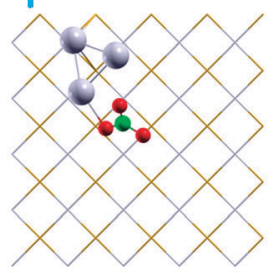

$M D 900^{\circ} \mathrm{K}$

Fig. 2 Possible hopping mechanisms of $\mathrm{Ag}_{3}\left(\mathrm{CO}_{3}\right)$ over the $\mathrm{MgO}(100)$ surface: (a-c) rotation; (d-f) translation. (a), (d) initial configurations; (c), (f) final configurations; (b), (e) saddle points. Atom color coding as in Fig. 1.

We therefore perform a few runs of ab initio MD at temperatures ranging from 300 to $1200 \mathrm{~K}$ and lasting $10-20$ picosecond, and extract information regarding the possible disruption and diffusion routes. The $\mathrm{Ag}_{3}\left(\mathrm{CO}_{3}\right) / \mathrm{MgO}(100)$ catalytic complex proves to be rather robust from these simulations. No breaking of the complex is ever observed during the MD runs, which (considering fluctuations) allows us to set $\approx 1.5 \mathrm{eV}$ as a lower value of the disaggregation energy barrier. Hopping movements are instead observed. Some of these present a very low energy barrier, such as the one depicted in Fig. 2a-c, whose $E_{\mathrm{b}}$ is equal to $0.4 \mathrm{eV}$ from an explicit NEB calculation, but are non-diffusive as they correspond to on-site rotation of the complex. Others present a higher energy barrier, such as the one depicted in Fig. 2d-f, whose $E_{\mathrm{b}}$ is crucial for catalyst stability and has then been estimated via an accurate NEB calculation to be $=0.85 \mathrm{eV}$, and correspond to real diffusive paths which allow the complex to move over the surface. These latter movements are detrimental to the catalyst stability, as they can lead to cluster sintering. The energy barriers of diffusive modes are much higher than the corresponding ones for the bare $\mathrm{Ag}_{3}$ cluster over $\mathrm{MgO}(100)$, which are around $0.11 \mathrm{eV},{ }^{28}$ and this is strictly connected with the stronger interaction of the carbonate ligand with the oxide surface. The ligand/cluster complex is therefore more stable with respect to diffusion and sintering because of the ligand adhesion to the substrate. Despite this, the values of diffusive barriers are still a bit low to fully protect the catalysts against sintering. Among other factors, this is due to the facility (or the moderate energy penalty) with which the $\mathrm{CO}_{3}$ 'bidentate' adsorption mode transforms into the 'bridge' one, see Fig. 1 and 2.

Let us elaborate on the issue of ligand/cluster diffusion. The energy barriers of the corresponding hopping moves strongly depend on the catalytic-complex/oxide-surface interaction, which in turn depends on the strength of the electrostatic forces developing between the two systems. Therefore we may expect that the energy barriers of hopping moves can be increased substantially e.g. in passing from $\mathrm{Mg}^{++}$to a higher-valence metal cation such as $\mathrm{Al}^{3+}$. Moreover, even though this is more speculative, substrate geometrical asperities may also be expected to disfavor such movements with respect to the regular $\mathrm{MgO}(100)$ surface, because a rougher surface presents physical valleys or depressions from which it can be more difficult for the catalytic complex to escape (especially for rigid oxides, whereas more flexible ones such as ceria may possess rearrangement modes which can couple with diffusion of the catalytic species). Point defects such as double vacancies ${ }^{29}$ can be assimilated to geometrical asperities. Extended but more regular defects such as surface steps may also play a role in hindering diffusion moves, although the increase in the complex-substrate interaction strength associated with these defects with respect to the regular surface is usually not so large, so that they may be insufficient to prevent diffusion of the catalytic aggregate. If correct, these arguments then suggest why $\mathrm{Ag}_{3}$ (or better, the corresponding catalytic species for the specific reaction there investigated) is a reasonably stable catalyst on an oxide which is both of higher-valence and rougher such as amorphous alumina, as shown in ref. 4.

It can be recalled that defects other than purely geometrical ones have often been advocated as important nucleation and trapping centers for metal nanoclusters. For example, a popular model derived from surface science ultra-high-vacuum (UHV) studies invokes the presence of point defects such as oxygen vacancies or $\mathrm{F}_{\mathrm{s}}$ (color)-centers, ${ }^{3}$ and indeed such defects are able to efficiently trap metal clusters. ${ }^{29}$ However, in agreement with previous studies, ${ }^{30}$ we found that a surface neutral oxygen vacancy on $\mathrm{MgO}(100)$, being a very high-energy defect, does not survive under oxidative conditions. In detail, we found the following reaction sequence:

$$
\begin{aligned}
\mathrm{Ag}_{3} / \mathrm{Fs}-\mathrm{MgO}(100)+\mathrm{CO}+\mathrm{O}_{2} & \rightarrow \mathrm{Ag}_{3} / \mathrm{Fs}-\mathrm{MgO}(100)(\mathrm{CO})\left(\mathrm{O}_{2}\right) \\
& \rightarrow \mathrm{Ag}_{3} / \mathrm{Fs}-\mathrm{MgO}(100)(\mathrm{OCOO}) \\
& \rightarrow \mathrm{Ag}_{3} / \mathrm{Fs}-\mathrm{MgO}(100)(\mathrm{O})+\mathrm{CO}_{2} \\
& \rightarrow \mathrm{Ag}_{3} / \mathrm{MgO}(100)+\mathrm{CO}_{2}
\end{aligned}
$$

where the $\mathrm{Ag}_{3} / \mathrm{Fs}-\mathrm{MgO}(100)$ starting point represents a silver trimer adsorbed onto a neutral oxygen vacancy on the regular $\mathrm{MgO}(100)$ surface. For convenience of the reader, the last step of this sequence, $\mathrm{Ag}_{3} / \mathrm{Fs}-\mathrm{MgO}(100)(\mathrm{O}) \rightarrow \mathrm{Ag}_{3} / \mathrm{MgO}(100)$, is pictorially illustrated in Fig. 3. In other words, the $\mathrm{Ag}_{3} / \mathrm{Fs}-\mathrm{MgO}(100)$ cluster can absorb $\mathrm{CO}$ and $\mathrm{O}_{2}$ and catalyze the formation of an OOCO intermediate species, which can then evolve $\mathrm{CO}_{2}$, thus leaving behind an oxygen adatom, but at this point a strong thermodynamic driving force of $-3.48 \mathrm{eV}$ enables the $\mathrm{O}$ adatom to fill the vacancy. ${ }^{30}$

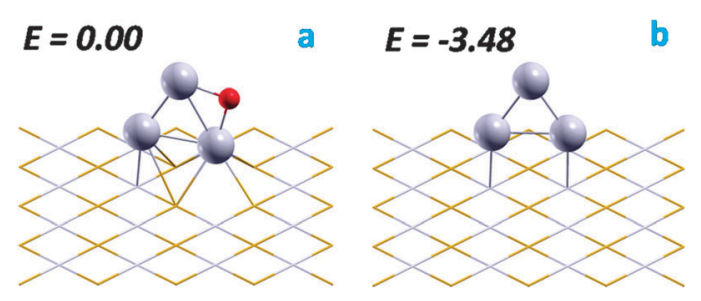

Fig. 3 Healing of an oxygen vacancy by an oxygen adatom adsorbed onto $\mathrm{Ag}_{3} / \mathrm{F}_{\mathrm{s}}-\mathrm{MgO}(100)$ (a), i.e., $\mathrm{Ag}_{3}$ supported on an $\mathrm{F}_{\mathrm{s}}$-defected $\mathrm{MgO}(100)$ (b) surface, thus transforming it into $\mathrm{Ag}_{3} / \mathrm{MgO}(100)$, i.e., $\mathrm{Ag}_{3}$ supported on the regular $\mathrm{MgO}(100)$ surface (b). Energies are in $\mathrm{eV}$. Atom color coding as in Fig. 1. 
The surface oxygen vacancy is thus healed by the oxygen adatom, see Fig. 3. This may be occurring not only on simple oxides such as $\mathrm{MgO}(100)$, but also more in general; a similar process and phenomenon has been observed in theoretical simulations even on reducible oxides such as ceria. ${ }^{31}$ The $\mathrm{Ag}_{3} / \mathrm{MgO}(100)$ species resulting from healing of the defect is not bound to any trapping center and is thus very mobile. ${ }^{28} \mathrm{It}$ will therefore likely to sinter, ${ }^{30}$ questioning the possibility that an oxygen vacancy can really act as a trapping center for $\mathrm{Ag}_{3}$ on $\mathrm{MgO}(100)$ under oxidative conditions. The influence of oxygen vacancies on the properties of oxides as catalytic supports (especially simple oxides) might thus have been overestimated, as pointed out in previous work, ${ }^{32}$ and more systematic investigations on the formation energy of surface oxygen vacancies and their reaction with oxygen adatoms on the metal ultrananoclusters would be interesting. In contrast, the proposed $\mathrm{Ag}_{3}\left(\mathrm{CO}_{3}\right) / \mathrm{MgO}(100)$ catalytic complex is robust with respect to adsorption of an oxygen adatom, as shown in ref. 10 and 16. From the above analysis it also seems to be reasonably stable with respect to disaggregation, and also diffusion - even though only at intermediate temperatures - a rougher and higher-valence substrate is probably necessary to stabilize this class of $\mathrm{Ag}_{3}$-based catalytic species with respect to sintering at high temperatures. ${ }^{4}$

\section{C. Formation of the NOox catalytic complex from the COox one}

We start from the $\mathrm{Ag}_{3}\left(\mathrm{CO}_{3}\right) / \mathrm{MgO}(100)$ catalytic complex shown in Fig. 2a, and we consider $\mathrm{NO}$ and $\mathrm{O}_{2}$ adsorption and co-adsorption. Adsorption energy is defined as the difference between the total energy of the system minus the sum of the energies of the fragments in their relaxed configurations. $\mathrm{NO}$ and $\mathrm{O}_{2}$ adsorption onto this complex is energetically favorable, but by a small amount, the corresponding adsorption energies are 0.73 and $0.15 \mathrm{eV}$ in the 'top' and 'base' adsorption modes, respectively. It should be noted that unless explicitly indicated we always report electronic energies, which must be corrected for entropic and other contributions to calculate free energies under the given experimental conditions. In the following discussion we include the translational contribution only, assuming that rotovibrational contributions to reaction free energy and energy barriers are compensated, as is often the case at room temperature. The translational free energies of $\mathrm{NO}, \mathrm{O}_{2}$, and $\mathrm{NO}_{2}$ in the gas phase at the pressures given in Section 2, and assuming ideal-gas behavior are $0.56,0.45$, and $0.58 \mathrm{eV}$, respectively, and will be subtracted from the electronic adsorption energies to obtain adsorption free energies. Co-adsorption of $\mathrm{NO}$ and $\mathrm{O}_{2}$ is also favorable, with a total energy gain of $-1.18 \mathrm{eV}$. As shown in Fig. $4 \mathrm{a}$ and $\mathrm{b}$, the most favorable co-adsorption configuration is $\mathrm{NO}$ in 'top' and $\mathrm{O}_{2}$ in 'base', switching the two molecules increases the energy by $0.36 \mathrm{eV}$. NO and $\mathrm{O}_{2}$ in the most stable co-adsorption mode are in a proper configuration to produce a OONO intermediate according to a Langmuir-Hinshelwood mechanism as shown in Fig. 4b-d, much in the same way that $\mathrm{CO}$ and $\mathrm{O}_{2}$ give rise to the OOCO intermediate in COox. ${ }^{33}$ Again, in fair analogy with the COox case, the OONO intermediate further evolves - see Fig. $4 \mathrm{~d}-\mathrm{f}$ - into an oxygen adatom and a $\mathrm{NO}_{2}$ species. However, at variance with the COox chemistry over

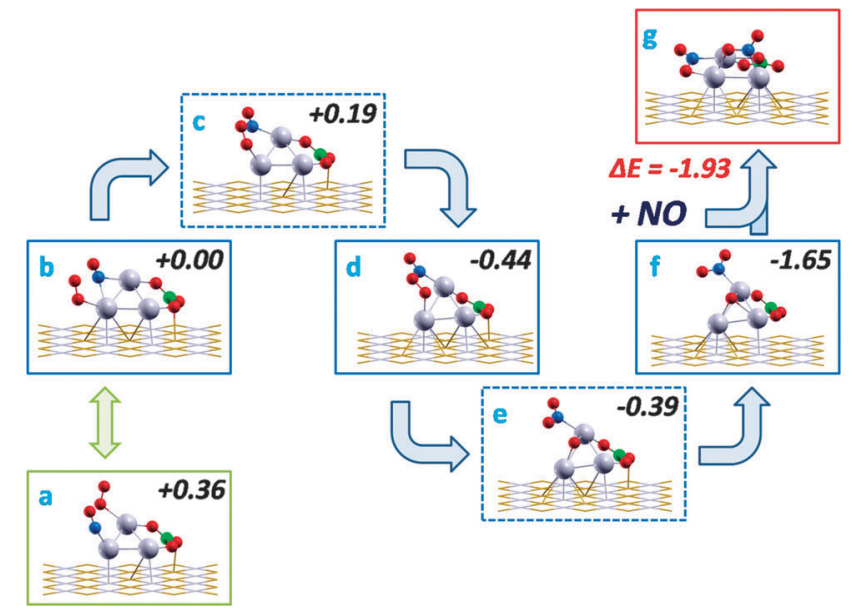

Fig. 4 Formation of the mixed carbonate/double-nitrite $\mathrm{Ag}_{3}\left(\mathrm{CO}_{3}\right)\left(\mathrm{NO}_{2}\right)_{2} /$ $\mathrm{MgO}(100)$ ligand/cluster/support complex under NOox conditions starting from $\mathrm{NO}$ and $\mathrm{O}_{2}$ co-adsorbed onto $\mathrm{Ag}_{3}\left(\mathrm{CO}_{3}\right) / \mathrm{MgO}(100)$. Numbers in the boxes correspond to energies (in eV) relative to configuration (b). Boxes surrounded by continuous lines contain local minima, those enclosed in dashed lines contain saddle points. Energies are in eV. Atom color coding is the same as in Fig. 1.

$\mathrm{Ag}_{3}\left(\mathrm{CO}_{3}\right) / \mathrm{MgO}(100)$, the $\mathrm{NO}_{2}$ species is adsorbed rather strongly, by $0.93 \mathrm{eV}$, and therefore does not leave the aggregate as a free molecule under the given experimental conditions. The resulting $\mathrm{Ag}_{3}\left(\mathrm{CO}_{3}\right)(\mathrm{O})\left(\mathrm{NO}_{2}\right) / \mathrm{MgO}(100)$ complex can absorb another NO molecule, which directly reacts with the oxygen adatom to produce a mixed carbonate/double-nitrite $\mathrm{Ag}_{3}\left(\mathrm{CO}_{3}\right)\left(\mathrm{NO}_{2}\right)_{2} / \mathrm{MgO}(100)$ complex with an energy gain of $-1.93 \mathrm{eV}$. $\mathrm{NO}_{2}$ desorption from this complex is thermodynamically unfavorable, as it increases the energy by more than $0.9 \mathrm{eV}$. Such a complex is therefore a stable species with respect to stoichiometry. In the next subsection we show that it can act as a NOox catalyst.

\section{D. The NOox catalytic cycle over the $\mathrm{Ag}_{3}\left(\mathrm{CO}_{3}\right)\left(\mathrm{NO}_{2}\right)_{2} /$ $\mathrm{MgO}(100)$ catalytic complex}

Fig. 5 shows the proposed NOox catalytic cycle over the $\mathrm{Ag}_{3}\left(\mathrm{CO}_{3}\right)\left(\mathrm{NO}_{2}\right)_{2} / \mathrm{MgO}(100)$ ligand/cluster/support catalytic complex. This cycle is obtained by incrementally adsorbing $\mathrm{NO}$ and $\mathrm{O}_{2}$ onto the complex and calculating reaction energy barriers whenever they are appreciable (adsorption of ligands from the gas phase is often barrierless in terms of electronic energy). The first step $(5 \mathrm{a} \rightarrow \mathrm{b})$ corresponds to NO adsorption; this is energetically favorable by $-0.53 \mathrm{eV}$, and will become basically thermodynamically neutral when the loss of NO translational free energy $(0.56 \mathrm{eV})$ is subtracted. In the next step $(5 \mathrm{~b} \rightarrow \mathrm{c})$, an $\mathrm{O}_{2}$ molecule from the gas phase is adsorbed according to the Eley-Rideal mechanism and forms an OONO intermediate passing through an energy barrier of $0.31 \mathrm{eV}$. A simultaneous rearrangement of the neighboring $\mathrm{NO}_{2}$ adsorbate from a 'base bidentate' to a 'base' mode can also be appreciated. The final gain in electronic energy in this step is $-0.17 \mathrm{eV}$, so that an increase in free energy of $0.28 \mathrm{eV}$ is associated with this step. Overcoming an energy barrier of $0.19 \mathrm{eV}$ the system then converts into a $\mathrm{Ag}_{3}\left(\mathrm{CO}_{3}\right)\left(\mathrm{NO}_{2}\right)_{3}(\mathrm{O}) / \mathrm{MgO}(100)$ complex, with an 


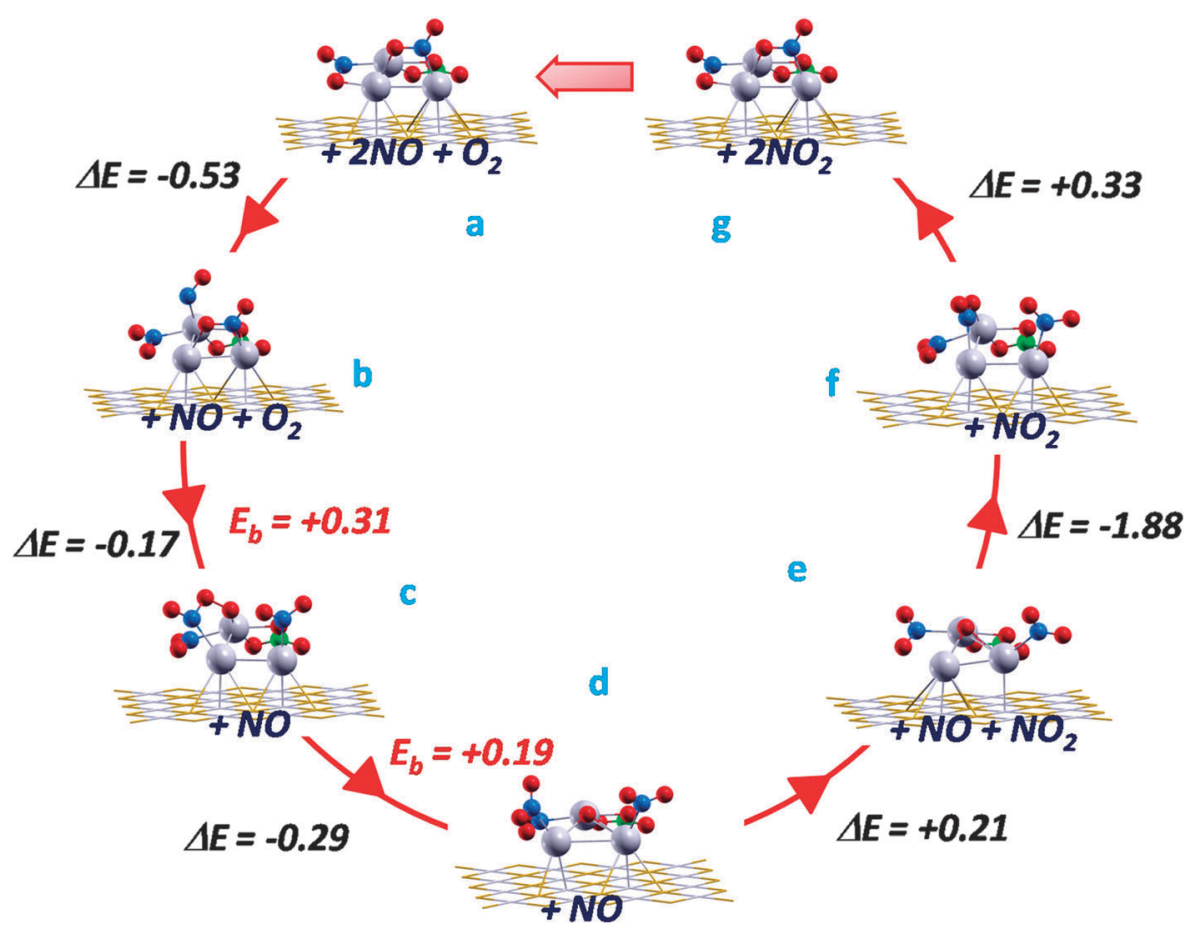

Fig. $5 \mathrm{NOox}$ catalytic cycle $\left(2 \mathrm{NO}+\mathrm{O}_{2} \rightarrow 2 \mathrm{NO}_{2}\right)$ over the mixed carbonate/double-nitrite $\mathrm{Ag}_{3}\left(\mathrm{CO}_{3}\right)\left(\mathrm{NO}_{2}\right)_{2} / \mathrm{MgO}(100)$ catalytic complex. $\Delta E$ are reaction energy differences, while $E_{\mathrm{b}}$ are reaction energy barriers. Energies are in eV. Atom color coding as in Fig. 1.

energy lower by $-0.29 \mathrm{eV}(5 \mathrm{c} \rightarrow \mathrm{d})$ and thus basically regaining thermodynamic neutrality. The process $5 \mathrm{~b} \rightarrow \mathrm{d}$ corresponds to the rate-determining step of the proposed catalytic cycle. Evolving $\mathrm{NO}_{2}$ from this complex is energetically costly by only $0.21 \mathrm{eV}(5 \mathrm{~d} \rightarrow \mathrm{e})$, whose electronic contribution is compensated by the increase in $\mathrm{NO}_{2}$ translational entropy to obtain a free energy gain of $-0.37 \mathrm{eV}$. The resulting $\mathrm{Ag}_{3}\left(\mathrm{CO}_{3}\right)\left(\mathrm{NO}_{2}\right)_{2}(\mathrm{O}) / \mathrm{MgO}(100)$ species can absorb NO, which reacts with the oxygen adatom giving rise to a very stable $\mathrm{Ag}_{3}\left(\mathrm{CO}_{3}\right)\left(\mathrm{NO}_{2}\right)_{3} / \mathrm{MgO}(100)$ species $(5 \mathrm{e} \rightarrow \mathrm{f}$ ), with an electronic energy gain of $-1.88 \mathrm{eV}$. This species can finally evolve $\mathrm{NO}_{2}$ into the gas phase thus regenerating the $\mathrm{Ag}_{3}\left(\mathrm{CO}_{3}\right)\left(\mathrm{NO}_{2}\right)_{2} / \mathrm{MgO}(100)$ catalytic complex and closing the cycle; $0.33 \mathrm{eV}$ must be paid at the electronic level, but are compensated by the $\mathrm{NO}_{2}$ translational entropic increase of $0.58 \mathrm{eV}$ to obtain a free energy gain of $-0.25 \mathrm{eV}$. In summary, the overall free energy barrier for the whole process is predicted by the present DFT approach to be $0.28(5 b \rightarrow c)+0.19$ $(5 \mathrm{c} \rightarrow \mathrm{d})=0.47 \mathrm{eV}$; this roughly corresponds to a kinetic rate of the order of tens of microseconds at room temperature, which is interesting from an application point of view.

\section{Conclusions}

The present work lies within the general topic of the catalytic chemistry of subnanometer (or ultranano) metal clusters supported on oxide substrates (in other words, the field of heterogeneous ultrananocatalysis) and focuses in particular on the $\mathrm{Ag}_{3}\left(\mathrm{CO}_{3}\right) /$ $\mathrm{MgO}(100)$ catalytic complex which is formed over $\mathrm{Ag}_{3} / \mathrm{MgO}(100)$ under CO oxidation (COox) conditions. ${ }^{10}$ We first show that its disaggregation presents a significant energy barrier, while its dif- fusion is considerably slower than that of bare $\mathrm{Ag}_{3}$ due to the electrostatic interaction with the support. We also show that $\mathrm{Ag}_{3}$ on a defected $\mathrm{MgO}(100)$ surface presenting an oxygen vacancy is not a stable catalyst under oxidation conditions as it spontaneously transforms into $\mathrm{Ag}_{3} / \mathrm{MgO}(100)$, which can then quickly diffuse and sinter, whereas $\mathrm{Ag}_{3}\left(\mathrm{CO}_{3}\right) / \mathrm{MgO}(100)$ is robust with respect to further oxidation. Moreover, we take a step further and explore the possibility that $\mathrm{Ag}_{3}\left(\mathrm{CO}_{3}\right) / \mathrm{MgO}(100)$ can work as the catalyst of a different reaction, i.e. the selective oxidation of $\mathrm{NO}$ to $\mathrm{NO}_{2}$ (or NOox). The specific example considered here is a severe test of the transferability of a catalytic species due to the complex chemistry of the NOox reaction and its diversity with respect to COox. Indeed, interestingly we find that a different aggregate actually forms under reaction conditions, i.e., a mixed carbonate/double-nitrite $\mathrm{Ag}_{3}\left(\mathrm{CO}_{3}\right)\left(\mathrm{NO}_{2}\right)_{2} /$ $\mathrm{MgO}(100)$ species. Such a species is then found to be capable of acting as the catalyst of NOox, with an overall free energy barrier of $0.47 \mathrm{eV}$, and thus show an expected significant catalytic activity.

The present results prove the diversity of the catalytic chemistry of subnanometer (or ultranano) metal clusters deposited on oxide substrates, point out the need for systematic structural and stoichiometric searches with the ability to cope with such a complex diversity, and open new combinatorial paths of pairing catalytic complexes/reactions to both experimental and theoretical investigations. ${ }^{32}$

\section{Outlook}

The starting point of the present investigation is the concept of the ligand/metal-cluster/support catalytic complex. ${ }^{7,10,16}$ 
This concept unifies both the influence of the oxide support and high-coverage effects into a single idea, and corresponds to a mechanism which is advocated to be generally operative in heterogeneous ultrananocatalysis. The role of ligands in the formation of such catalytic complexes is decisive and is underlined here. They are called to partially fill the strongly unsaturated coordination environment of the metal ultrananoclusters ${ }^{9}$ and to protect the catalytic aggregate from disruption, but without losing the fluxional character of these ultrananospecies and the possibility of further ligand adsorption which are necessary for catalytic functioning. They also contribute to catalyst stability by increasing adhesion to the oxide substrate by e.g. electrostatic or ionicbonding interactions thus preventing sintering.

In the present paper, we explore the next step in this line of research, i.e., is it possible to use the catalytic complex derived for one catalytic reaction as the catalyst in a different reaction?

This attempt seems to be promising in several respects. For example, it emulates catalyst preparation in real-world catalytic systems, thus possibly shed some light on what often appear as 'black magic' protocols. ${ }^{10}$ It can also be put in accordance with the beneficial effect of trace dopants or promoters - see e.g. ref. 34-36 for disparate examples - as due to the formation of an appropriate surface aggregate in heterogeneous catalysis in which the dopant (like the $\mathrm{CO}_{3}$ in the present case) does not necessarily take part in the reaction, yet it is essential in forming the catalytically active complex on the surface. Finally, it opens the way to a vast number of possible combinations between the catalyst and reaction.

This proposal is not a routine step forward, and indeed in the present work we find that the resulting picture is more complex than expected, and that in the presence of different ligands (especially ligands with a completely different chemistry such as NO with respect to the previously investigated $\mathrm{CO}$ ) the original catalytic complex is drastically altered, and the system evolves from $\mathrm{Ag}_{3}\left(\mathrm{CO}_{3}\right) / \mathrm{MgO}(100)$ into a $\mathrm{Ag}_{3}\left(\mathrm{CO}_{3}\right)\left(\mathrm{NO}_{2}\right)_{2} /$ $\mathrm{MgO}(100)$ complex - a strikingly unexpected result.

We believe that the present findings expand our basic knowledge on the catalytic chemistry of supported subnanometer metal clusters, and we trust that they will spur research to find novel catalytic systems that are able to meet the present societal challenges in activity and selectivity. ${ }^{1}$

\section{Acknowledgements}

We thank Leonarda Liotta, Prasenjit Sen and Stefan Vajda for stimulating discussions. Financial support from the ERC-AG SEPON project is gratefully acknowledged. Use of the Center for Nanoscale Materials was supported by the U. S. Department of Energy, Office of Science, Office of Basic Energy Sciences, under Contract No. DE-AC02-06CH11357.

\section{References}

1 L. N. Lewis, Chem. Rev., 1993, 93, 2693-2730.

2 J. H. Sinfelt, Acc. Chem. Res., 1987, 20, 134-139.
3 A. Sanchez, S. Abbet, U. Heiz, W.-D. Schneider, H. Häkkinen, R. N. Barnett and U. Landman, J. Phys. Chem. A, 1999, 103, 9573-9578.

4 Y. Lei, F. Mehmood, S. Lee, J. Greeley, B. Lee, S. Seifert, R. E. Winans, J. W. Elam, R. J. Meyer, P. C. Redfern, D. Teschner, R. Schlogl, M. J. Pellin, L. A. Curtiss and S. Vajda, Science, 2010, 328, 224-228.

5 G. Kwon, G. A. Ferguson, C. J. Heard, E. C. Tyo, C. Yin, J. DeBartolo, S. Seifert, R. E. Winans, A. J. Kropf, J. Greeley, R. L. Johnston, L. A. Curtiss, J. Pellin and S. Vajda, ACS Nano, 2013, 7, 5808-5817.

6 P. Bihouix and B. de Guillebon, Quel Futur pour les métaux? Raréfaction des métaux: un nouveau défi pour la société, EDP Sciences, Les Ulis Cedex A, France, 2010.

7 F. R. Negreiros, G. Barcaro, L. Sementa and A. Fortunelli, C. R. Chim., 2014, 17, 625-633.

8 G. A. Ferguson, F. Mehmood, R. B. Rankin, J. P. Greeley, S. Vajda and L. A. Curtiss, Top. Catal., 2012, 55, 353-365.

9 S. G. Kwon, G. Krylova, A. Sumer, M. M. Schwartz, E. E. Bunel, C. L. Marshall, S. Chattopadhyay, B. Lee, J. Jellinek and E. V. Shevchenko, Nano Lett., 2012, 12, 5382-5388.

10 R. Negreiros, L. Sementa, G. Barcaro, S. Vajda, E. Apra and A. Fortunelli, ACS Catal., 2012, 2, 1860-1864.

11 H.-J. Freund, Surf. Sci., 2002, 500, 271-299.

12 S. Klacar, N. M. Martin, J. Gustafson, S. Blomberg, Z. Liu, S. Axnanda, R. Chang, E. Lundgren and H. Grönbeck, Surf. Sci., 2013, 617, 167-174.

13 S. K. Megarajan, S. Rayalua, Y. Teraokab and N. Labhsetwara, J. Mol. Catal. A: Chem., 2014, 385, 112-118.

14 M. Koebel, G. Madia and M. Elsener, Catal. Today, 2002, 73, 239-247.

15 A. Boubnov, S. Dahl, E. Johnson, A. P. Molina, S. B. Simonsen, F. Mo. Cano, S. Helveg, L. J. Lemus-Yegres and J.-D. Grunwaldt, Appl. Catal., B, 2012, 126, 315-325.

16 F. R. Negreiros, E. Apra, G. Barcaro, L. Sementa, S. Vajda and A. Fortunelli, Nanoscale, 2012, 4, 1208-1219.

17 P. Giannozzi, S. Baroni, N. Bonini, M. Calandra, R. Car, C. Cavazzoni, D. Ceresoli, G. Chiarotti, M. Cococcioni, I. Dabo, A. Dal Corso, S. De Gironcoli, S. Fabris, G. Fratesi, R. Gebauer, U. Gerstmann, C. Gougoussis, A. Kokalj, M. Lazzeri, L. Martin-Samos, N. Marzari, F. Mauri, R. Mazzarello, S. Paolini, A. Pasquarello, L. Paulatto, C. Sbraccia, S. Scandolo, G. Sclauzero, A. P. Seitsonen, A. Smogunov, P. Umari and R. M. Wentzcovitch, J. Phys.: Condens. Matter, 2009, 21, 395502.

18 J. Perdew, K. Burke and M. Ernzerhof, Phys. Rev. Lett., 1996, 77, 3865-3868.

19 D. Vanderbilt, Phys. Rev. B: Condens. Matter Mater. Phys., 1990, 41, 7892-7895.

20 G. Henkelman, B. P. Uberuaga and H. Jonsson, J. Chem. Phys., 2000, 113, 9901-9904.

21 J. Hutter, M. Iannuzzi, F. Schiffmann and J. VandeVondele, Wiley Interdiscip. Rev.: Comput. Mol. Sci., 2014, 4, 15-25.

22 G. Lippert, J. Hutter and M. Parrinello, Theor. Chem. Acc., 1999, 103, 124-140.

23 S. Goedecker, M. Teter and J. Hutter, Phys. Rev. B: Condens. Matter Mater. Phys., 1996, 54, 1703-1710. 
24 J. VandeVondele and J. Hutter, J. Chem. Phys., 2007, 127, 114105.

25 G. Martyna, M. Klein and M. J. Tuckerman, Chem. Phys., 1992, 97, 2635-2643.

26 Cambridge Structural Database www.ccdc.cam.ac.uk/Solutions/ CSDSystem/Pages/CSD.aspx.

27 R. Ferrando, A. Fortunelli and R. L. Johnston, Phys. Chem. Chem. Phys., 2008, 103, 640-649.

28 G. Barcaro and A. Fortunelli, New J. Phys., 2007, 9, 22.

29 G. Barcaro and A. Fortunelli, in Metal Clusters and Nanoalloys From Modeling to Applications, ed. M. M. Mariscal, O. A. Oviedo and E. P. M. Leiva, Springer, New York, 2012, pp. 29-79.
30 S. Abbet, U. Heiz and H. Hakkinen, Phys. Rev. Lett., 2001, 86, 5950-5953.

31 S. Santra, P. K. Hota, R. Bhattacharyya, P. Bera, P. Ghosh and S. K. Mandal, ACS Catal., 2013, 3, 2776-2789.

32 J. M. Thomas, J. Chem. Phys., 2008, 128, 182502.

33 Y. Gao, N. Shao, Y. Pei and X. C. Zeng, Nano Lett., 2010, 10, 1055-1062.

34 J. Yu, Chem. Commun., 1998, 1103-1104.

35 J. Chen, J. A. H. Sander, J. Halin, C. Schouten and T. A. Nijhuis, Faraday Discuss., 2011, 152, 321-336.

36 T. C. R. Rocha, M. Hävecker, A. Knop-Gericke and R. Schlögl, J. Catal., 2014, 312, 12-16. 